\title{
MDRS Crew 110A - Summary Report
}

\author{
Aaron Olson, Julie Mason \\ University of Wisconsin-Madison \\ Engineering Physics and Mechanical Engineering Departments
}

\section{Crew Members}

Julie Mason, Crew Commander

Aaron Olson, Crew Engineer, Mission Specialist

Sam Marron, Chief Astronomer, Crew Health and Safety Officer

Lyndsey Bankers, Crew Engineer, Mission Specialist

Mark Ruff, Crew Engineer, Journalist

Will Yu, Chief Engineer

Crew Rotation December 31 - January 7, 2011

The crew would like to thank the Wisconsin Space Grant Consortium (WSGC), the UWMadison Dean of Engineering, their faculty advisor Dr. Frederick Elder, and the Mars Society Mission Support for their knowledge, guidance, and support of the mission. We could not have accomplished our goals without you.

Crew 110A consisted of a team of engineers, undergraduates and graduate students, from the University of Wisconsin-Madison. During our stay, we celebrated the New Year with an inaugural midnight EVA and red Martian cool-aid, we anxiously listened to the UW-Madison Badger Football Team play in the Rose Bowl, and we completed 15 EVA's within a seven day period.

The crew set out with a mission to conduct habitability, atmospheric, geologic imaging, and space suit ergonomic studies and a vision to advance the space industry's exploration capabilities.

The team worked with a NASA lead human factors engineer to design a habitat architecture study, a member from ESA on 3D imaging, and a professional astronomer. The crew also looked at habitable space for crew exercising and made outreach videos for upcoming middle school and high school visits.

Contributions by Lyndsey Bankers, Sam Marron, Will Yu and Mark Ruff Financial support provided by the Wisconsin Space Grant Consortium 
As commander, I was honored to have such a great crew. The crew worked long hours during the daytime EVA's, collecting images and videos, as well as stayed awake through long hours of the night to collect data at the Musk Mars Desert Observatory and complete 3D models.

\section{Summary of Mission's Accomplishments}

\section{EVA's:}

- Over 20,000 Telescope Images

- Over 500 Photos for 3D Model

- 4 Outreach Videos

\section{D Imaging Summary}

The purpose of the 3D modeling project was to explore the ability to create a 3D model of the surrounding area of the MDRS habitat with Autodesk's 123D Catch, a free online program that utilizes "the cloud" to compute 3D models from arrays of images. Such a model could be used by future researchers at MDRS to plan robotic traverses and could also be shared online through YouTube and Google Earth when completed. 123D Catch was also used to create models of crew members, small objects inside and outside of the habitat and remote geographical features. In the seven days of the study, images were taken during EVAs and then uploaded and processed when the internet communication limitations weren't in effect. The results of the 3D models varied due to image exposure, the program's ability to match features in different images and the amount of manual image "stitching" performed. The main 3D model was a model of a 200 foot radius about the habitat. As suspected, 123D Catch was capable of creating the model with some success, but in order to make the model to scale and without gaps in the mesh; quite a bit of manual image stitching (locating matching points in multiple images) and model re-processing was needed. Over 30 hours of work was done during the stay at MDRS to get acquainted with the 123D Catch program and to try to better the model. More work will be done before the model is sent out to interested people and posted online. It is clear that the program is much better suited to model areas smaller than the 400 foot diameter circular area used for this project, I would recommend to others interested in using this software for a similar purpose to make models of smaller areas and then compile them into larger models using other 3D modeling programs (Autodesk 3DMax...etc.)

\section{Atmospheric Monitoring Summary}

The astronomy study conducted by MDRS crew 110a aims to estimate the amount of extinguishing material in the atmosphere. This is achieved by tracking and imaging of celestial objects such as stars and planets throughout the night. As a celestial object appears to pass through the sky as the night progresses, the amount of atmosphere through which the light passes changes. Imaging of these objects with the imaging astronomer kit in the MDRS observatory allows us to track the intensity of the light as a function of the angle off the horizon. We recorded 
images near the start of each hour through the nights starting 1/4/2012/ and 1/5/2012. We recorded at least 6 images of Jupiter, Sirius, Rigel, and Polaris.

The data recorded for Jupiter and Sirius best fit the expected trends. We learned that images of Rigel were easily oversaturated which resulted in a loss of light intensity data. Larger, dimmer celestial bodies provided better light intensity data. Polaris does not change its angle relative to the horizon, and was imaged as a control in order to track unexpected changes in atmospheric extinguishing. We recorded weather data for each hour of each recording night; this includes temperature, humidity, dew point, and cloud cover percentage. Post-mission analysis will allow us to gauge our imaging accuracy and comment on which factors contribute to and prohibit accuracy, including the class of object being imaged, temperature data, and the frequency and location of imaging.

\section{Exercise Study Summary}

The goal of the exercise study is to learn about the effects of exercise on habitability and productivity of the crew. The exercises chosen for this study all utilize body weight and therefore do not require any extra equipment or space in the habitat. The exercises focus on strength and are not meant to tire crew members out, but to ensure that each major muscle group stays strong throughout missions.

Throughout the week various crew members exercised in both the upper and lower levels of the habitat with no problems with crowding of the space. Workouts were modified as the week went on based on how each crew member felt and what they liked and disliked about previous workouts.

\section{Habitat Architecture Summary}

The team designed a habitat architecture study to gather human-in-the-loop performance data on the habitat at Mars Desert Research Station.

Data will be compared to habitat architecture studies conducted at NASA Desert Research and Technology Studies (Desert RATS). At Desert RATS 2011, group members, Samuel Marron, Aaron Olson, and Julie Mason participated in an engineering evaluation of NASA's Habitat Demonstration Unit—Deep Space Habitat in Flagstaff, Arizona.

The habitat architecture study examined habitat architecture, requirements, and operations to advance understanding in these critical areas. The results will enhance the human performance data collected during several habitat evaluations conducted at Desert RATS. Habitat questionnaires will be completed at the end of the field test at MDRS by each study participant.

\section{Journalist Summary}


On any future mission to Mars, there will need to be an element of public outreach. Public support is critical to the space program as a whole and even more critical to the major projects in manned spaceflight, such as a mission to Mars. If we are to avoid the "flags and footprints" missions of the Apollo era as we venture to Mars, it will be critical that we ensure that the public is engaged.

This is why journalism is a critical part of any Mars mission. A trained journalist can report information to the public in a manner far more palatable than a crew member without such experience, and thus, ensure the public's ongoing engagement with the Mars program.

This would appear to present a problem, when crew sizes for most missions currently under proposal range between 3 and 6 . There simply isn't room on such a small crew for a dedicated journalist. However, as was learned here at MDRS, this is also not a full-time role. As crew journalist, I come from an engineering background, but also have experience with communications. While working at the research station, I worked on a number of studies and assisted the chief engineer, all in addition to my role as crew journalist, all together representing a perfectly reasonable workload.

While serving as crew journalist, I chronicled crew events and activities, many of which were mentioned in the daily reports. A point was also made of getting quality pictures of the landing site, the crew, and any other image that would help engage the public.

It was determined on this mission that journalism is critical to the continued success of a Mars program. However, this does not require that other elements of the mission be hindered by placing a dedicated journalist on the crew. A technician or scientist already suited to the crew could likely be trained in the necessary communication skills to fill this role. 